\title{
A CiteSpace-Based Visual Analysis and Review of Research Literature in Area of Elderly Reemployment
}

\author{
Wenwei Chow ${ }^{1 *}$, Derong Lin $^{2}$ \\ ${ }^{1}$ School of Management, Xiamen University, Xiamen 361000, China; \\ ${ }^{2}$ School of Management, Xiamen University, Xiamen 361000, China. \\ * Corresponding author
}

Keywords: Elderly reemployment; population ageing; visual analysis; review paper

\begin{abstract}
In the context of the increasing trend of population ageing in China and the increasing influence of "silver hair wave ", researches on population ageing and elderly reemployment are growing fast. This article makes a visual analysis of the research literature in CNKI(China National Knowledge Internet) on elderly reemployment by using the method of keyword co-occurrence analysis in CiteSpace software, and systematically combs these researches. It reviews and analyzes the researches in several perspectives, such as reasons for reemployment, influencing factors of reemployment intentions, reemployment characteristics, cross-cultural study, and measures to promote reemployment. It reveals that more empirical researches shall be made in future studies, by a more scientific process, in a more rigorous way, and from a more open and deep perspective.
\end{abstract}

\section{Introduction}

In 2000, China entered into an ageing society, and the year 2012 was recognized as the beginning of the gradual contraction of China's demographic dividend [1]. Population ageing has become a realistic and serious problem for China. In recent years, the growing trend of population ageing in China has caused a threat to and an impact on our country's economic health and sustained development.

From another point of view, a large amount of the elderly human resources is also a valuable resource, faced by the current labor shortage, pension deficit and other problems, and before the forthcoming policy of extending retirement age in China. For this reason, elderly reemployment has become an important topic and has produced a considerable amount of literature made by domestic scholars on the analysis of factors affecting the elderly reemployment and factors affecting their reemployment intentions.

The large amount of literature, however, is not systematic and has different conclusions. Therefore, it is necessary to comb these conclusions in a comprehensive and systematic way and organize them with an appropriate framework for the solution of population ageing and for the development of the elderly human resources.

\section{Overview of Total Research Literature}

A search was made in this study on November 17, 2017 with CNKI using thematic words "reemployment for the elderly people" or "reemployment for the elderly" based on the full text database of Chinese periodicals, the full text database of Chinese excellent master's theses and the full text database of Chinese doctoral dissertations, including all literature of the past years. Literature type was limited to review articles and research articles. In the searched 299 articles, after manual deletion of meeting notifications and task interviews, 291 articles including 246 journal papers, 5 doctoral dissertations and 40 master's theses were obtained. Among the 291 articles, there are 7 supported by national social science fund, 1 supported by National Natural Science Fund, 1 supported by scientific research fund of the Hubei Provincial Education Commission, and 1 supported by scientific research fund of the Liaoning provincial education department. In the articles, 110 were published in domestic core periodicals, 56 published in CSSCI periodicals.

For contribution units of the 291 articles, 8 were contributed by Peking University, 7 by Jilin University, 6 by Capital University of Economics and Business, 6 by Renmin University of China, 5 by Zhongnan 
University of Economics and Law, and 5 by East China Normal University. For subjects of the 291 articles, the top five in quantity are sociology and statistics, macro-economic management and sustainable development, talent science and labor science, Chinese politics and international economy, and demography and family planning.

\section{Overview of Total Research Literature}

Key words of high frequency are often used to determine hot topics in a research field. Therefore, the key words in the articles about elderly reemployment are analyzed for their concurrence to discuss the hot topics in this area.

The analysis was made firstly using the software CiteSpace with the time range from 1986 to 2017, the time slice 1 year, the text run at default, the node type keyword, the keyword frequency threshold 30, the key network structure algorithm Pathfinder. After that, a co-occurrence map of keywords with 66 nodes and 171 connecting lines was obtained (see Fig. 1), in which a round node means a key word, with its size representing the frequency of the key word. The size of the label in the figure is proportional to the occurrence frequency of the word. The size of the line between the nodes reflects the degree of cooperation and tightness between the key words in this field. A circle with a thick edge means a hot research topic. The hot research topics are population ageing, elderly reemployment, elderly population, elderly talent, and birth rate. It can be seen that the topic "population ageing" connected with the topic of the elderly reemployment is an important research area. The "population birth rate" is a hot topic of research, but it has a far relationship with "elderly reemployment" and "population ageing".

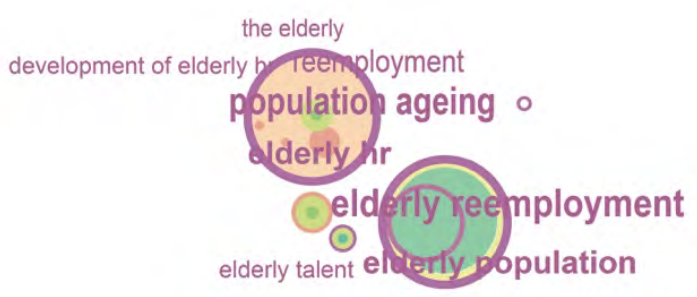

Fig. 1 Co-occurrence map of keywords

Cluster analysis of the map produced 5 obvious clusters (See red characters in Figure 2) and a list of keyword frequency. The module value $\mathrm{Q}=0.5429>0.3$, which was convincing; and the contour value $\mathrm{S}=0.5041>0.5$, which indicated that the clusters were reasonable. 


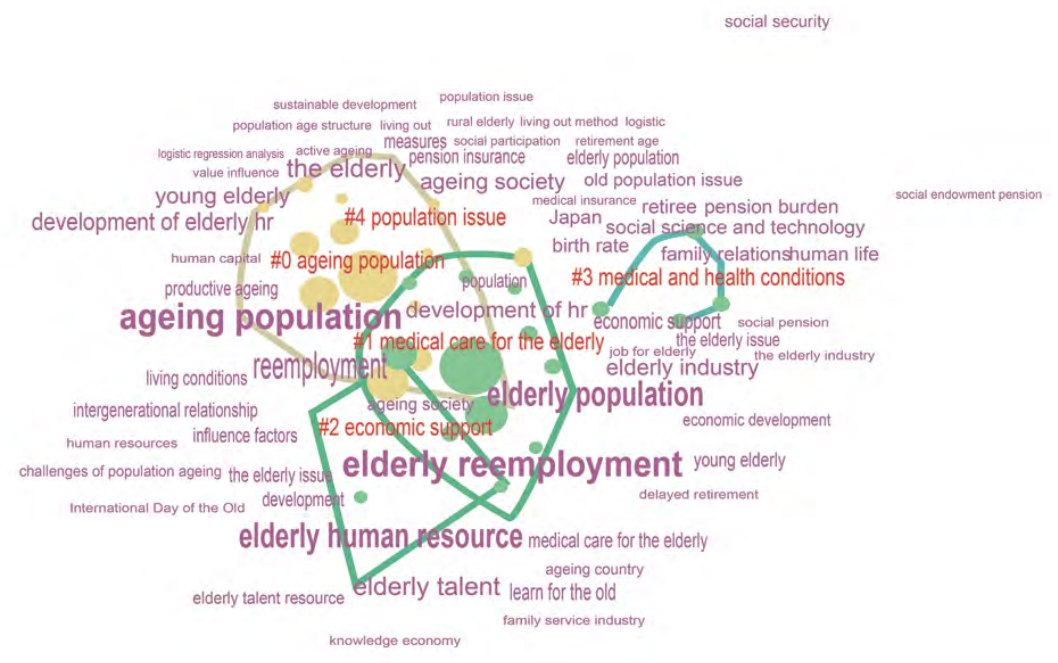

Fig. 2 Cluster map of key words

\section{Summary of Reasons for Elderly Reemployment}

\subsection{Summary of necessities for development of elderly human resources}

From the above visual analysis, we can see that "population ageing" is a hot research topic. It is precisely because of the ageing of the population that the development of elderly human resources is specially necessary.

Population ageing in China has the characteristics of not rich and old [2, 3] and unprepared and lonely old $[3,4]$, which means that the ageing of the population has turned the labor force of our country from "unlimited supply" to "limited surplus".

Population ageing has brought many problems, such as an old age structure [5], inadequate labor force, reduced labor resources, and a declined labor resource rate [6]. The consequent increased elderly maintenance coefficient [2, 5, 6] has further amplified the endowment insurance [5, 7], medical expenses, nursing costs, social welfare and relief costs and other old-age service expenses $[5,8]$.

Development of elderly human resources is one of the important ways to deal with the ageing of the population $[9,10,11]$. It is also an important method to alleviate the shortage of labor force $[4,7,12,13]$. By this development, the young and healthy elderly people can work in their old age, which not only reduces social burden $[10,14]$ and creates conditions for the elderly to realize their values of life, but also helps to establish a healthy and optimistic social environment for population ageing [10].

The elderly have advantages over young people in terms of experience, knowledge and skills [2, 10, 15, 16]. The elderly have advantages of politics, economics, knowledge, time and space, high seniority and high prestige according to Duan Xianlai [17]. The elderly human resource is an important part of human resources in China [16]. Giving play to the advantages of the elderly can bring a positive effect to social and economic development and alleviate their adverse effects [18]. At present, however, a large number of retirees who still have labor force are eliminated from labor resources, which is a waste of human resources $[6,8,17,19,20]$.

\subsection{Study on reasons for elderly reemployment}

The concept of elderly reemployment was put forward by Dong Shigui [21]. From an economic view, the elderly reemployment contributes to the accumulation of human capital stock [22, 23], which can not only change the structure of labor supply, but also improve the savings and stimulate social consumption [24]. Development of elderly talent is the lowest in cost and the fastest in time [17]. From a sociological view, the elderly reemployment is beneficial to social participation, social identification, and the consequent improvement of the sense of happiness [25]. From a demographic view, the reemployment of the elderly meets their needs to continue to participate in social activities and learning, which is conducive 
to the prolongation of life and the period of self-reliance [26]. From the perspective of reality, the retired elderly have a strong desire for employment, and their main purpose of reemployment is to increase income and divert from emotional loneliness [27].

$\mathrm{Li}$ Xiaohui thinks that the elderly reemployment is to relieve their children's support pressure and realize their own value [28]. Jin Yi thinks that the motives of elderly reemployment include needs of economy, spiritual sustenance, work, and devotion of special skills [13]. For these needs, this scholar divides them into life need, social relations need, self-esteem need, knowledge need, and self fulfilling need referring to Maslow's theory of hierarchy of needs, the humanistic needs of Clayton Alderfer of Yale University, and the need points of Fromm (E. Fromm) and Professor Chen Zhishang.

Shi Jinzhi thinks that the elderly reemployment is beneficial to self support, happiness and health, which could also alleviate the burden to the family brought by the ageing of the population [15].

Liu Fan thinks that the amount of income affects the quality of life [16]. For the elderly with low pension income and without other economic sources, increasing income is their main cause of reemployment.

Mostly the motivation for employment of the elderly is to obtain economic compensation, which is showed in many scholars' researches [13, 29, 30,31]. Some scholars explained from different angles the reasons for reemployment of the elderly. Zhu Hao and Yi Longfei studied the baseline data of the China Health and Retirement Longitudinal Study (CHARLS) of 2011 [32]. They analyzed the pension insurance and medical insurance related to the elderly to investigate the impact of social insurance on the reemployment of the young elderly in urban and rural areas.

\section{Study on Factors Influencing Reemployment Intention of the Elderly}

Qian Xin and Jiang Xiangqun used the data obtained from A single survey on the status of elderly population in urban and rural areas in China made by the CRCA(China Research Center for Ageing) in China in 2000 [33]. They selected $10 \%$ data obtained from the survey and analyzed the factors affecting the employment intention of the elderly in urban China. It demonstrated that age, health status and economic conditions are significant whilst education level is not particularly significant. It also indicated that the male urban elderly have a significantly stronger sense of labor participation than the female urban elderly.

Jiang Wei used the survey data of A survey of elderly population in urban and rural China in 2010 to conduct a study for Chaoyang District of Beijing, which concluded that gender, age, education and economic status of the elderly have significant impacts on their employment intention [34].

Wang Peng selected the relevant data from China's Comprehensive Social Survey (2010), a questionnaire based survey, which involved 28 provinces and cities in the eastern, central and western regions of China, both rural and urban [30]. His study showed that gender, age, health condition, constant feeling of loneness and economic conditions had a significant influence on the reemployment intention of the urban elderly.

Lu Lin and Lan Zhuhong found that social participation also had an impact on the reemployment intention of the urban elderly [27].

Many scholars made questionnaires to collect data for their research. Using crossover tables and logistic regression analysis, they established Logistic model to analyze the factors influencing the reemployment intention of the elderly, with the results shown in Table 1.

Table 1 Factors influencing reemployment intention

\begin{tabular}{|c|c|c|}
\hline Scholar & Research area & Research conclusion \\
\hline $\begin{array}{l}\text { Tian Lifa et al } \\
{[24]}\end{array}$ & Tianjin City & $\begin{array}{l}\text { Reemployment intention decreases with age, increase with education level. The } \\
\text { retired from government-affiliated institutions have little desire for reemployment, } \\
\text { and the retired from unstable positions have strong desire for reemployment. When } \\
\text { the income can not meet the daily expenses or the children support their } \\
\text { reemployment, the elderly will choose reemployment. In addition, there is no } \\
\text { significant difference in reemployment intention between the elderly engaged in } \\
\text { management post and those in non management post before their retirement. Gender } \\
\text { difference is not significant. Health status is not significant. }\end{array}$ \\
\hline
\end{tabular}




\section{Cont.to Table 1}

Zhao Qiwu [35] Beijing City

Wang Kun[36] M District, Shenzhen

Lin Gang [37] Shandong Province Wang Chengjie Four cities of Shandong
[38]

Yang Xiao[39] Xi'an City

Work place before retirement and children's attitude to reemployment are significant; gender, education level, position before retirement and income before retirement are not significant.

Age, professional skills and education background are significant factors; gender, pension and relationship with children have an impact on the reemployment of the elderly, but not significant.

Gender, age, health status, economic status, and skills have significant influence on the reemployment intention of the urban elderly. Education level has no significant influence.

Age, health status and professional skills, the three factors, have significant effect on the reemployment intention of the urban elderly. Gender, education level and economic status have no significant impact.

The significance of gender and health status was verified. The four variables of age, economic status, educational level and skill/specialty failed to pass the significance test.

After controlling other variables, age, education level, health status, pension are significant factors. There are gender differences in age, health status and other elderly work. Awareness of law, living out conditions, living place and the time spent with their children have no significant impact on reemployment decision.

Shi Lingyun et Shanghai City
al [40] Skills, economic status and age have significant influence on reemployment intention

\begin{tabular}{ll}
$\begin{array}{ll}\text { Fang } \\
\text { Yuruozhou[41] }\end{array}$ & $\begin{array}{l}\text { Skills, economic status and age have significant influence on reemployment intention } \\
\text { of the elderly; Gender and education have no significant influence. }\end{array}$ \\
\hline China (excluding &
\end{tabular}

Zhao Liqing Shanghai, Hunan,

[42] Guangdong, Qinghai, Hong Kong, Macao and

Age, health condition, skills and pension have significant influence on reemployment of the elderly; Gender, economic status and education degree are not significant. Taiwan)

\section{Reemployment Features}

Normally, the male elderly have a higher proportion of reemployment than the female elderly, the young elderly is higher than the old elderly, the first industry is higher than the other industries. The first industry is mainly in agriculture, and the third industry is mainly in service area, commerce area and professional/technical work [13, 35, 37, 43, 44]. The main method of job hunting in reemployment is to rely on a strong relationship network [45], firstly by introduction of friends or the former boss, secondly rehired in the former employer or introduced to a new employer by a work agency [46].

Yang Xinke and Jin Wenjun think that in the reemployment the elderly usually choose jobs clearly distinct from the working age population, such as counseling, individual consultation, public service etc., which are not usually suitable or attractive to young people [10]. The employment of the elderly in these jobs could not only fill the vacancies, satisfy the needs of the society, but also provides opportunities for the elderly to realize their values. It is an integrated, supplementary and indispensable component of the employment with working age population as the main part.

Zhang Yi and Li Jiangying believe that for the elderly, the reemployment positions normally demand not so much in skills [45]. Jia Guonian believes that for normal reemployment, the elderly shall consider their expertise, experience, and especially their physical conditions and energy [47].

Some scholars are concerned about the relationship between the elderly reemployment and specific industries. Li Pengbo believes that the relatively low proportion of elderly human resources in hotel industry prove that hotels and other traditional service industries shall strengthen the development and utilization of the elderly resources [48]. Fortunately, the elderly normally have rich knowledge, plentiful life experience and social connections, high psychological maturity, strong responsibility, good stability and other advantages, which means that the elderly human resources can be developed at low cost and do not need too much pre job training. Therefore, to a certain extent, the elderly is a good solution for the problems in hotel industry, such as immature young employees, ineffective incentive measures, poor stability and so on. 


\section{Cross-Cultural Study}

Wang Shuxin early carried out a comparative analysis of employment of the elderly population [49]. He detailed the influence of retirement age and reemployment remuneration on the elderly employment, and made a comparative analysis of the employment rate of the elderly in some countries.

Cui Yingchun and Zhang Yanxia compared and analyzed the structure of the working age population, employment change rate of the elderly women, industry distribution characteristics and characteristics of the employment form [50]. They found that in China the status and the functions of the elderly female working population in the labor market are obviously inferior than Japan. To promote employment of elderly women, China shall provide a solid legal guarantee, and improve the health service system for the elderly. In addition, China shall make more efforts and attempts to promote the social security system as well as the fairness and sustainability of the employment system for the elderly.

Zheng Enshan systematically compared and analyzed the elderly labor market and the elderly reemployment in China and South Korea by the horizontal comparative analysis method [51]. There are similarities in the purpose of reemployment in both countries, which is to meet their needs of survival, improve their living conditions and fit into social development. Additionally, the author also put forward countermeasures to handle problems faced by countries and enterprises.

$\mathrm{Li}$ Meihua thinks that the three countries of China, Japan and South Korea belong to the Confucian culture circle and therefore share many similarities [52]. Japan and South Korea encountered the problem of population ageing in the period of rapid economic development. Therefore, it has a strong reference for China to analyze the policies of Japan and South Korea to deal with population ageing and elderly employment.

The vast majority of developed countries have entered the ageing society, all of which are same in cherishing the elderly human resources and promoting their reemployment. Although the experiences of the developed countries to cope with population ageing originated from their own situations, they are undoubtedly a valuable reference for China, which is in the early and rapid development stage of the population ageing. At present, there are many scholars who analyzed the related experiences of the developed countries and brought important enlightenment to the elderly human resources and their reemployment in China [4, 13, 16, 37, 42].

In general, the cross-cultural study on elderly reemployment is relatively few and shallow for China's scholars. Most of their articles only draw lessons from other countries' experience, with few in-depth heterosexual research articles on two countries.

\section{Measures to Promote Reemployment}

Zhao Junyan put forward suggestions on the development of elderly human resources: providing a good operating environment, developing the ageing industry, developing the employment market for the elderly, setting up an elderly talent market and an elderly talent bank, providing vocational education and training for the elderly, implementing a "late in and late out" employment model, and gradually changing the traditional pension and insurance methods [53].

Xiong Bin and Yang Jiangrong think that the development of elderly human resources needs support in policies and public opinions [54]. Firstly, the government needs to lead and develop plans and methods for the development of elderly human resources, establish a bank of the elderly human resources, and build a network of these resources; secondly, the retirement system shall be amended and reformed accordingly.

Zhao Fei suggests establishing a development system at three levels [7]. Firstly, government orientation, to consolidate the social foundation for the development of the elderly human resources; secondly, market leading function, to broaden the development channel, open up the pension insurance market, and firmly defend the development of the elderly human resources; thirdly, quality improvement of the aged population, to excavate the potential of the elderly human resources, and implement the strategy of "develop the talent through science and education." 
Qu Gonghe thinks that the government shall take the development and utilization of the elderly human resources as an important premise to support and promote the economic and social development [55]. In addition, it shall be monitored and assessed as a target of government management to normalize and institutionalize this work gradually.

Liu Dan suggests establishing necessary facilities and organizations for the elderly, such as database of the elderly talent, agencies for communication, service and intermediary, talent markets, associations and commissions, in order to safeguard and protect the legitimate rights and interests of the elderly, and communicate their requirements and suggestions [46]. At the same time, we should vigorously publicize to eliminate the various prejudices against the participation of the elderly in social and economic activities, and create a good environment for the development of the elderly talent resources.

$\mathrm{Yu}$ Hong thinks that the government, enterprises and the elderly need to shoulder their respective responsibilities [56]. The government undertakes the role of supporters and helpers, by creating a good atmosphere of public opinion, speeding up the establishment of specific and operational laws, protecting the legitimate rights and interests of the elderly, perfecting elderly retraining system, and supporting the establishment of elderly universities. Enterprises take the role of employers and developers, by creating a harmonious and respectful working environment, paying attention to the physical and mental health of the elderly, protecting their legitimate rights and interests, and providing retirement plans for the retiring workers. The elderly themselves should constantly recharge and update their knowledge so as to better their reemployment.

Yang Hutao and Tian Ying think that enterprises can establish a human resource management system to explore the elderly resources [57]. A technical expert group system and an old staff education and training system could be established to renew and update the knowledge and skills of the aged employees, and consequently increase the employability of the retired employees and create greater value for the enterprises. At government level, they suggest to formulate Code of reemployment guarantee for the elderly and Code of anti-discrimination for the elderly reemployment in order to safeguard and protect the elderly, to improve the Labor law, to increase relevant provisions, to establish an arbitration system, and to establish a database for the elderly as an information platform for the supply and demand. At the social level, they suggest to open a mode of cooperation between enterprises and elderly organizations or between enterprises and the elderly.

\section{Summary}

Researches on reemployment for the elderly still have a long way to go, and the researches shall not only realize "know it", but also need to "know it so". Therefore, future researches can choose one or more factors and explore the process or mechanism of their affecting.

In addition, comparative analysis can be used among different countries, different regions and different industries for the study of experiences in elderly reemployment. Some countries and regions (for example, Germany and Japan) have already experienced population ageing earlier than our country, have accumulated some good experiences and methods, and underwent shortcomings. Therefore, drawing lessons from their experiences and shortcomings is an important way for us to better carry out the reemployment for the elderly.

To sum up, we need to carry out more empirical researches, by a more scientific process, in a more rigorous way, and from a more open and deep perspective.

\section{References}

[1]. Q. Song and Y. Qi, "Practice and inspiration in development of elderly human resources in Japan," Human Resources Development of China, 2013, (19), pp. 83-87.

[2]. S. M. Sun, "Develop silver resources -- an option in the face of population ageing," Northwest Population Journal, 2003, (04), pp. 40-43. 
[3]. G. Z. Mu and T. Zhang, "Development trend and strategic response of population ageing in China," J Huazhong Norm Univ (Hum Soc Sci), 2011, 50(05), pp. 29-36.

[4]. X. Cheng, “A study on development of elderly human resources in China in background of population ageing,” Qingdao University, 2008.

[5]. D. L. Zhang, Q. H. Lu, and L. Y. Ma, “Thoughts of population ageing and sustainable development,” China Population Resources and Environment, 2001, (S1), pp. 93-95.

[6]. B. J. Xiong, "Population ageing and development and utilization of elderly human resources in China," Chinese Journal of Gerontology, 1990, (05), pp. 257-259.

[7]. F. Zhao, "Population ageing and development of elderly human resources in China,” Jilin University, 2004.

[8]. X. G. Chen, “Population ageing, elderly population and other issues,” Yunnan Gao Jiao Yan Jiu, 1995, (03), pp. 18-21.

[9]. Y. J. Chen, "Speculations on development of elderly human resources,” Journal of Hainan Normal University (Social science edition), 2011, 24(02), pp. 159-162.

[10]. X. K. Yang and W. J. Jin, "Speculations on development of young elderly human resources," Journal of Lanzhou University, 2001, (03), pp. 168-172.

[11]. L. Wang and Y. L. Wang, “Analysis of development of elderly human resources in China,” Journal of Changsha University, 2010, 24(06), pp. 31-33.

[12]. J. J. Pan and C. P. Cheng, “A study on development of young elderly human resources in China,” Contemporary Economy \& Management, 2013, 35(03), pp. 65-71.

[13]. Y. Jin, “A study on development of elderly human resources in China in background of population ageing,” Jilin University, 2012.

[14]. Q. H. Tian and B. Li, “A new way to improve social security -- preliminary discussion on promoting self-support of the elderly,” Journal of Industrial Technological Economics, 1999, (01), pp. 39-40+43.

[15]. J. Z. Shi, "Sustainable development of social economy promoted by development of elderly talent resources,” Northwest Population Journal, 2000, (03), pp. 44-46.

[16]. F. Liu, “A study on reemployment of urban elderly in China in background of population ageing,” Jilin University, 2013.

[17]. X. L. Duan, "Speculations on development of elderly human resources,” Talent Exploration, 2000, (11), pp. 36-38.

[18]. S. X. Wang and Y. Yang, "Strategic thoughts on development of elderly human resources," Population Research, 2005, (03), pp. 63-69.

[19]. G. Z. Mu, “The Elderly: load or wealth?” Chinese Journal of Sociology, 1994, (06), pp. 41-43.

[20]. L. Shan and X. Y. Luo, "Reemployment of retired people in background of population ageing," Reform \& Opening, 2017, (20), pp. 77-78.

[21]. S. G. Dong, “On the reemployment of the retired,” Academic Journal of Zhongzhou, 1988, (06), pp. 39-40+36.

[22]. N. Y. Yuan, “A Research on transmission mechanism of extending retirement age affecting human capital,” Population \& Economics, 2011, (04), pp. 29-34+57. 
[23]. C. B. Zeng, “A research on reemployment ability of the young urban elderly from the perspective of human capital,” Sichuan Academy of Social Sciences, 2012.

[24]. L. F. Tian, H. L. Shen, M. H. Zhao, and W. W. Zhang, "A survey on factors influencing reemployment intentions of urban elderly: case in Tianjin,” China Economic Studies, 2014 (5), pp. 30-38.

[25]. B. A. Song and T. Q. Yu, "Influence of urban elderly reemployment on happiness -- study of elderly population in Jilin Province,” Population Journal, 2011 (1), pp. 42-46.

[26]. B. Chen and C. G. Lan, "National specific strategies for promoting employment of aged workers in OECD countries,” Population and Development, 2015, 21(01), pp. 96-101.

[27]. L. Lu and Z. H. Lan, “An analysis of factors influencing the employment intention of urban elderly in China: Based on the population survey of urban and rural elderly in China in 2010," Northwest Population Journal, 2015, 36(04), pp. 90-95.

[28]. X. H. Li, “An analysis on elderly reemployment in China -- Based on a survey of the elderly in a county of Fujian Province,” Journal of Liaoning University of Technology (Social science edition), 2016, 18(02), pp. 12-15.

[29]. L. Yu, L. Y. Ma, X. D. Yin, and B. Fleisher, "Support or NEET? --A study on reemployment of elderly in China,” Studies in Labour Economics, 2016, (5), pp. 24-54.

[30]. P. Wang, “A study on reemployment of urban elderly in China in background of population ageing," Dongbei University of Finance \& Economics, 2016.

[31]. X. Y. Wang, “A study on employment of urban young elderly,” University of Jinan, 2011.

[32]. H. Zhu and L. F. Yi, "Influence of social insurance on reemployment of urban and rural elderly people in young age-- An empirical analysis based on CHARLS data,” Northwest Population Journal, 2015, 36(03), pp. 53-58.

[33]. X. Qian and X. Q. Jiang, “An analysis of factors influencing employment intention of urban elderly in China,” Population Journal, 2006, (05), pp. 24-29.

[34]. W. Jiang, “An analysis of factors influencing reemployment intention of the elderly in Beijing," Journal of Shanxi Agricultural University (Social science edition), 2013, 12(01), pp. 104-108.

[35]. Q. W. Zhao, "Development of young elderly human resources in Beijing in background of population ageing,” Beijing Jiaotong University, 2017.

[36]. K. Wang, “A study on reemployment of young elderly human resources from the perspective of active ageing,” Shenzhen University, 2017.

[37]. G. Lin, “A study on development of elderly human resources in background of population ageing," Shandong University of Finance and Economics, 2012.

[38]. C. J. Wang, “A study on development of elderly human resources in China in background of population ageing,” Shandong University of Finance and Economics, 2016.

[39]. X. Yang, “An analysis of factors influencing elderly reemployment in Xi'an,” Co-Operative Economy \& Science, 2017, (07), pp. 84-85.

[40]. L. Y. Shi and X. R. Xie, “A study on influencing factors of reemployment of retired urban elderly: a case of Shanghai,” China Labour, 2017, (09), pp. 56-60.

[41]. Y. R. Z. Fang, “A study on development of elderly human resources in background of population ageing in China,” Yanshan University, 2015. 
[42]. L. Q. Zhao, “An empirical study on influence factors of development of urban elderly human resources in China: case of national statistical data,” Social Scientist, 2015, (11), pp. 53-57.

[43]. W. W. Liu, "Development of Elderly human resources in background of population ageing," Modern Economic Information, 2016, (01), pp. 104.

[44]. D. Q. Xie and X. Q. Xu, “Thoughts of employment of the elderly population in China,” Reform of the Economic System, 2001, (02), pp. 157-160.

[45]. Y. Zhang and J. Y. Li, "Strong relationship network and reemployment of retired elderly population,” Chinese Journal of Population Science, 2000, (02), pp. 34-40.

[46]. D. Liu, "Situation and Countermeasures for productive ageing in background of population ageing: case in Nanjing city,” Theoretic Observation, 2010, (02), pp. 59-60.

[47]. G. N. Jia, "Reemployment and old age life of the elderly,” Population Research, 1994, (02), pp. 49-54.

[48]. P. B. Li, "Hotel shall emphasize development and utilization of elderly human resources," Chinese Tourism Newspaper, 2017-04-06(A02).

[49]. S. X. Wang, “A comparative analysis of employment of the elderly across the world," Population Journal, 1992, (01), pp. 42-46.

[50]. Y. C. Cui and Y. X. Zhang, "A comparative study of employment of the elderly women in China and Japan,” Journal of Huazhong University of Science and Technology (Social science edition), 2016, 30(03), pp. 121-130.

[51]. E. S. Zheng, "Comparison of labour market and re employment of the elderly in China and Korea," Shandong University, 2010.

[52]. M. H. Li, "Study on population ageing and elderly employment policy in Korea and Japan,” Jilin University, 2014.

[53]. J. Y. Zhao, “A study on employment of the elderly in China,” Southwestern University of Finance and Economics, 2000.

[54]. B. Xiong and J. R. Yang, "Population ageing and development of Elderly human resources in China,” Journal of Chongqing Institute of Technology, 2002, (03), pp. 7-10.

[55]. G. H. Qu, "A study on development, utilization and countermeasures of elderly human resources," Policy Research \& Exploration, 2006, (07), pp. 16-17.

[56]. H. Yu, "Development and countermeasures of elderly human resources,” Modern Business Magazine, 2012 (9), pp. 257-258.

[57]. H. T. Yang and Y. Tian, "A research on shortage of human resources and development of "Silver age" talent resources: Wuhan city as an example,” Scientific Research on Ageing, 2014, 2(06), pp. 45-54. 